\title{
RITUALES DE HETZMEK EN YUCATÁN
}

\author{
Nancy Beatriz Villanueva Vill.anueva y Virginia Noemí Prieto
}

REsUmen: En este trabajo hacemos una revisión, sistematización y análisis de los estudios que se han realizado sobre los rituales de hetzmek en Yucatán, para que sirva como punto de partida a investigaciones etnográficas posteriores sobre las celebraciones actuales. Nos interesa conocer cómo han sido analizados e interpretados dichos rituales. Para ello, nos centramos en los siguientes aspectos: a) las presunciones que se han hecho sobre su origen, b) las problemáticas o temáticas teóricas dentro de las cuales se ha abordado, c) las funciones y los propósitos que los estudiosos le asignan y d) la manera en que realizan sus interpretaciones. Previamente, para que el lector conozca en qué consiste este ritual, presentamos una descripción basada en los rasgos más comunes e ideales. Finalmente, hacemos algunas reflexiones y recomendaciones metodológicas para futuros análisis de este ritual.

ABSTRACT: In this paper we review, systematize and analyze the studies that have been done on rituals of hetzmek in Yucatán, as a starting point for subsequent ethnographic research on this topic. We are interested in examining how these rituals have been analyzed and interpreted. Our focus is on: a) the assumptions that have been made about the ritual's origin, b) the theoretical problems within which it has been studies, c) the functions and purposes scholars have assigned to it, and d) how they have interpreted it. We start by presenting a description based on its ideal form and common characteristics in order for the reader to understand what the ritual consists of. Finally, we discuss some methodological points and make recommendations for future analyses of this ritual.

Palabras ClavE: hetzmek, cultura maya, ritos de paso, ciclo de vida, socialización, Yucatán, niños. KeY woros: hetzmek, Maya culture, passage rites, life cycle, socialization, Yucatan, children.

RECEPCión: 6 de noviembre de 2007.

ACEPTACIÓN: 20 de febrero de 2008. 



\title{
RITUALES DE HETZMEK ${ }^{1}$ EN YUCATÁN
}

\author{
Nancy Beatriz Villanueva Villanueva \\ Universidad Autónoma de Yucatán \\ Virginia Noemí Prieto \\ Universidad Autónoma de Yucatán
}

\section{Introducción}

En el mes de marzo de 2007, las autoras de este artículo fuimos a la localidad de Tiholop para asistir a la celebración de la ceremonia del hetzmek de Julia. Una de nosotras, Virginia Prieto, había sido invitada previamente por los padres de Julia para ser la madrina en esta ceremonia, debido a los lazos de amistad que había logrado entablar con ellos durante la realización de su investigación de campo en el albergue indígena de esa localidad. ${ }^{2}$ La oportunidad de observar muy de cerca dicho ritual, incluso desde la perspectiva de la observación participante, aunado a nuestro conocimiento previo del mismo, generó en nosotros la idea de hacer un recuento y análisis de los estudios que hasta hoy día se han hecho sobre el ritual del hetzmek, o que lo han incluido como parte de investigaciones más amplias.

El análisis del estado de la cuestión sobre el ritual del hetzmek estuvo motivado por el conocimiento que ya teníamos acerca de las diferentes acciones que el Gobierno del Estado de Yucatán, especialmente en la pasada administración (2001-2007), estuvo llevando a cabo con el objeto de reforzar o hacer resurgir las antiguas manifestaciones culturales de las poblaciones maya hablantes de Yucatán, entre ellas el ritual del hetzmek. Con esto el gobierno estatal intentó cumplir con la nueva política de revaloración de las culturas y las lenguas indígenas establecida constitucionalmente por el gobierno federal de México ${ }^{3}$ (Villanueva, 2008).

\footnotetext{
${ }^{1}$ En este documento utilizamos la palabra como aparece escrita en el trabajo de Alfonso Villa Rojas (1978). Cuando reproduzcamos citas textuales de otros autores, respetaremos las formas en que ellos la escriben.

${ }^{2}$ Los resultados de esta investigación serían presentados en noviembre de 2007 como tesis de licenciatura en Ciencias Antropológicas, con opción en Antropología Social, en la Facultad de Ciencias Antropológicas de la Universidad Autónoma de Yucatán, con el nombre de "Procesos de identificación étnica y socialización: niños y jóvenes de un albergue escolar indígena en Yucatán".

${ }^{3}$ Esta nueva política ha sido resultado de un proceso de cambios paulatinos hacia el mayor reconocimiento de las lenguas y culturas autóctonas del país, el cual inició en 1973 con el llamado indigenismo participativo. Estos cambios adquirieron mayor fuerza y peso con el reconocimiento de México como un país plurilinguie y pluricultural en las reformas a la Constitución Politica de los Estados Unidos Mexicanos en 1992 y luego con la promulgación de La ley Indígena de México en 2001.
} 
Por su nombre en lengua maya y su práctica preferentemente en poblaciones más tradicionales y con mayor porcentaje de maya hablantes, el Gobierno del Estado de Yucatán ha asumido que el ritual del hetzmek es de origen prehispánico y que, aunque en franco retroceso, aún pervive hasta nuestros días. Esta idea es compartida por representantes de organizaciones autonombradas como mayas. Recientemente, con motivo de un hetzmek celebrado en el centro ceremonial de la Santa Cruz en Xocén, Yucatán, el presidente de la organización Maya'On, quien fungió como padrino del bebé que fue objeto de ese ritual, manifestó a un reportero de un periódico local que:

el Jetsmeek se ha perdido poco a poco y son pocos, incluso en el medio rural, los que lo practican, motivo por el cual pretenden rescatar la tradición. La ceremonia del Jetsmeek es de origen prehispánico y tiene la función de fomentar el desarrollo intelectual y social de los niños mayas desde sus primeros meses de vida. Se dice que se debe cumplir con niñas y niños de menos de cinco meses (Diario de Yucatán del 7 de enero de 2006).

¿En qué se basa esta presunción? ¿Es resultado de la tradición oral? ¿Es efecto de las acciones que ha implementado el gobierno estatal en el marco de la nueva política cultural hacia la población maya hablante? ¿Puede ser incluso un "efecto de la teoría" 4 antropológica? Y es que la mayoría de los estudiosos de esta práctica cultural, o que la incluyen en sus análisis de procesos más amplios, han admitido igualmente su origen prehispánico ya sea implícita o explícitamente. Sin embargo, hasta donde hemos podido revisar, estos estudiosos no apoyan su afirmación con material arqueológico, iconográfico o procedente de documentos coloniales; se trata más bien de una deducción derivada de supuestos teóricos asumidos. Aunque ésta es una estrategia válida para el avance científico (no estamos defendiendo el empirismo), creemos que es necesario dejar sentado que se trata de una hipótesis teórica, que puede ser plausible, pero que hasta hoy no ha sido corroborada empíricamente. Investigaciones futuras, guiadas por esa hipótesis, en la medida en que indica caminos por dónde buscar evidencias, podrían hacerla más aceptable, o debilitarla.

Ante estos hechos nos ha parecido interesante revisar qué han dicho los estudiosos de la cultura maya sobre el ritual del hetzmek, cómo lo han analizado e interpretado, desde qué enfoque teórico lo han hecho, cuál es la problemática y la temática teórica y empírica en la que han insertado su análisis, cuáles son sus conclusiones. Como una de estas conclusiones es su origen prehispánico, analizamos cómo llegan a esta presunción. En este trabajo presentamos los resultados de nuestra revisión, sistematización y análisis de esos estudios con la finalidad de que puedan servir de base a una o más investigaciones etno-

\footnotetext{
"Bourdieu (1988: 132) utiliza el concepto de "efecto de teoría" para referirse a la utilización de la teoría social en la creación de hechos y realidades sociales. Menciona el caso de la constitución de las clases sociales como producto de un trabajo político que utiliza teorías para tal fin.
} 
gráficas sobre las celebraciones actuales. La idea es presentar un estado de la cuestión.

Antes de proceder al análisis y discusión de las propuestas de los estudiosos del ritual del hetzmek, a continuación describiremos en qué consiste este ritual, basándonos en las descripciones que sobre casos particulares se han hecho y en nuestras propias observaciones.

\section{Descripción del ritual del hetzmek}

En este apartado nos interesa dar a conocer al lector tanto la forma más común como la forma ideal en que se ha realizado este ritual doméstico entre los mayas yucatecos de los años treinta del siglo veinte y los actuales. ${ }^{5}$ Para reconstruir el modelo típico y el ideal hemos tomado los elementos más frecuentes en los rituales que han descrito los siguientes autores: Santiago Pacheco Cruz (1934), Roberth Redfield (1944), Roberth Redfield y Alfonso Villa Rojas (1962), Sylvanus Morley (1974), Alfonso Villa Rojas (1978), Eric Thompson (1979), Carlos Kirk (1982), Hilaria Máas Collí (1983 y 1986), Carmen Romero de Nieto (1986), MarieOdile Marion (1994), Alicia Peón Arceo (2000), Ella Fanny Quintal Avilés (2003), Patricia Fortuny Loret de Mola (2004) y Dolores Cervera Montejano (2006). Colateralmente mencionaremos algunas de las variaciones posibles que se alejan de la norma y de lo común. Aquí nos limitaremos a la descripción para que el lector tenga información de qué tipo de ritual estamos hablando. En el apartado 5 , discutiremos los significados que los propios participantes atribuyen a cada aspecto o elemento del ritual, y las interpretaciones de los estudiosos como resultado de su análisis simbólico. Para hacer esta descripción nos hemos basado en diversos autores:

El hetzmek es una ceremonia doméstica que, según manifiestan los padres, debe realizarse cuando las niñas cumplen tres meses de edad y los niños, cuatro. Sin embargo, esto no siempre es así; abundan casos en los que se celebra cuando los bebés ya tienen cinco meses de edad.

Esta ceremonia recibe su nombre de la forma en que se abraza a la criatura por primera vez, colocándola a horcajadas sobre la cadera izquierda de los adultos que han sido previamente invitados para ser padrino y/o madrina. Hetz o jéets quiere decir "aligerar", "aliviar la carga", y mek o méek se traduce como "abrazar". 6

\footnotetext{
${ }^{5}$ Abarcamos este amplio periodo porque los primeros escritos sobre el hetzmek de los que tenemos noticia son los descritos por Robert Redfield en 1934. Sin embargo, Villa Rojas (1978: 412-413) menciona un reporte previo de este ritual elaborado por Santiago Méndez en 1861, al cual no hemos tenido acceso.

${ }^{6}$ Nos llama la atención que el Diccionario Maya Cordemex (1980: 204) traduce la palabra maya hetzmek, que escribe con s en vez de $z$ (Hetsmek), como "el brazo en que se pone la cosa a horcajadas sobre la cintura". Esta traducción está muy alejada del uso actual y habitual de este término. Pero además incluye otras dos palabras con la misma raíz de hetzmek, cuya traducción es más cercana al uso de ésta: Hetsmek'tah ("sobarcar y sustentar, o llevar o traer los niños en brazos las indias, susten-
} 
Los padrinos generalmente deben ser dos, un hombre y una mujer, pero también puede ser sólo uno. En el último caso, el sexo del adulto debe corresponder con el sexo del infante; de modo que las niñas tienen madrina y los niños, padrino. Usualmente los padrinos son parientes de la familia o personas muy allegadas de la comunidad, con quienes se refuerzan los vínculos de compadrazgo. En el hetzmek de Julia que mencionamos al inicio, la madrina de la pequeña es extranjera, no obstante fue elegida por los padres de la niña para desempeñar tal función.

Esta ceremonia se puede realizar antes del bautizo de la criatura, el mismo día del bautizo o en fechas posteriores a esa celebración católica. Se reportan algunos casos en los cuales se elige el día de la ceremonia considerando la fase lunar; tres días antes de que llegue la luna llena, el día de luna llena, o tres días después de la misma, pero no se explica la razón de esto. Generalmente se realiza en la casa de los padres del niño; sin embargo, no faltan algunos ejemplos en los cuales se lleva a cabo en casa de los padrinos.

El día de la ceremonia los padres del niño preparan el espacio para el ritual. Se elige un lugar relativamente amplio en el interior de la casa o en el solar, y allí se coloca una mesa con mantel y sobre ésta una o más velas, un recipiente con flores, y los platos y jícaras con la comida que se dará a probar al niño o a la niña durante la ceremonia. En algunos casos se coloca sobre la mesa alguna imagen católica, como la de San Martín de Porres, la Santa Cruz Verde, la Virgen de Guadalupe.

La comida que se coloca sobre la mesa consiste fundamentalmente en pinole, ${ }^{7}$ huevo, pepita gruesa de calabaza. En algunos casos se pone además chaya (hervida y escurrida) y sal.

También se colocan sobre la mesa ciertos instrumentos de trabajo de acuerdo con el sexo de la criatura, los cuales le serán puestos en la mano durante el transcurso de la ceremonia. Entre éstos, los autores hacen referencia a machete, coa, jícara, sabucán y hacha si se trata de un niño; agujas, tijera, ollas y comal, si se trata de una niña. Para ambos se colocan libretas, libros, lápices y plumas. Más recientemente se han empezado a utilizar juguetes que imitan ser teléfonos celulares, computadoras portátiles, y otros.

Los padrinos llegan a la casa de los padres del niño con algunos presentes para el pequeño a quien se le realizará el hetzmek. En algunas descripciones se menciona que cuando se trata de una niña, la madrina comienza vistiéndola con la ropa que le han regalado los padrinos. En la ceremonia de Julia ocurrió de esta manera. Sin embargo, no hemos encontrado alguna mención similar cuando

tándolos; lo mismo es de los cántaros de agua y cosas así que los llevan sobre el hueso de la cadera") y Het it ("cargar, llevar a horcajadas a un niño por primera vez para éste, esto se hace entre los mayas con ciertas ceremonias y previo nombramiento de padrinos"). Es esta última palabra la que por su traducción refiere más exactamente al ritual del que aquí nos ocupamos.

${ }^{7}$ El pinole es un atole que se prepara con maiz (preferentemente nuevo) tostado y molido. Este polvo se mezcla con azúcar o miel y se pone a cocer con agua. 
quien recibe la ceremonia es un niño; por lo cual no sabemos si el padrino sería el encargado de vestirlo o siempre recaería esta función en la madrina, o en la madre cuando no hay madrina, por ser una actividad que culturalmente corresponde a la mujer.

Cuando la criatura ya está vestida, sus padres la llevan al lugar donde se realizará la ceremonia. Si se trata de una niña, la madre la entrega a la madrina, quien por primera vez le hará hetzmek. Cuando es un niño quien será objeto de este ritual, el padre lo entrega al padrino. Esto sucede en el momento en que el dirigente del ritual así lo indica. Por lo general éste es algún miembro anciano de la familia, que conoce mejor las fases del ritual. En pocos relatos se menciona al h'men como el dirigente de la ceremonia.

Una vez que la madrina recibe a la niña o el padrino al niño, de brazos de su madre, en el primer caso, y de su padre, en el segundo, el infante es colocado por primera vez a horcajadas sobre la cadera izquierda de la madrina o del padrino. En Tahmek, Yucatán, los padrinos reciben el nombre de madrina tzimin y padrino tzimin, por la postura en que los niños son colocados en la cadera de sus padrinos: tzimin es una palabra maya que significa "caballo". Los niños montan a sus padrinos.

Cuando el infante colocado en la posición de hetzmek es una niña, la madrina procede a dar nueve vueltas alrededor de la mesa. La primera serie de vueltas comúnmente se realiza girando en dirección de las agujas del reloj. Al finalizar esta primera serie de vueltas la madrina entrega la niña al padrino, quien también dará otras nueve vueltas, pero esta vez en sentido inverso. Dichas vueltas idealmente son contadas por la persona que dirige el ritual. En las descripciones consultadas se menciona a los abuelos paternos, las abuelas paternas o los propios padrinos. No obstante, es común que alguna persona cercana a la familia, aunque no necesariamente quien dirige el ritual, contabilice las vueltas dadas. Para esta operación utiliza granos de maíz, aunque también se mencionan casos en los que se utilizan hojas de chaya cruda o granos de cacao. En el hetzmek de Julia, la abuela paterna dirigió la ceremonia y contó las vueltas con ayuda de su nieto, el hermano mayor de la niña.

Cuando el infante que recibe la ceremonia de hetzmek es un niño, se procede de la misma manera, con la única diferencia de que las dos series constan de trece vueltas.

En el transcurso de las vueltas, tanto la madrina como el padrino le dan a probar al niño los alimentos que fueron colocados en platos o jícaras sobre la mesa principal.

En el hetzmek de Julia, la madrina, acompañada por alguno de los niños que se encontraban en la ceremonia, le daba a probar a la niña un alimento de los que estaban en la mesa, y simultáneamente repartía pepitas de calabaza tostadas entre los asistentes, quienes las comían y luego arrojaban la cáscara sobre la cabecita de la niña. Esto ocurrió por indicación de la dirigente. Ningún otro autor de los que hemos consultado menciona este hecho, lo cual no significa necesa- 
riamente que no se haga así en algún otro pueblo de Yucatán. Sin embargo, los autores sí reportan la presencia de este alimento en la mesa, y sólo Dolores Cervera (2006: 10) menciona que, por la edad de la bebé, no se la dieron a probar, y que ésta fue consumida por los invitados, pero no dice que conforme abrían la cáscara de pepita y consumían la parte comestible, le arrojaran las cáscaras a la cabeza de la bebé.

Complementariamente, durante la primera serie de vueltas, la madrina o el padrino, según el género del infante, va colocando en las manos de éste algunos de los instrumentos de trabajo que fueron depositados en la mesa, o debajo de ella, mientras le habla de su utilización en el trabajo que el niño desempeñará en el futuro. Existen reportes en los que se menciona, por ejemplo, que la madrina conduce a su ahijada a la cocina y allí le muestra y explica la utilidad de los utensilios. Luego la lleva al lavadero y procede de la misma manera. Con respecto a los niños, también encontramos una descripción en la cual el padrino lleva a su ahijado al campo. Allí le coloca en manos del infante instrumentos tales como la coa, el machete, una jícara. Toma la mano del niño y hace los ademanes del chapeo y el corte de leña.

Al finalizar las vueltas, el bebé es entregado a sus padres, quienes agradecen a los padrinos el haber hecho hetzmek a su hijo. Finalmente se reparten entre los asistentes — parientes y vecinos invitados_ los alimentos principales de la ceremonia, y en algunos casos se sirve una comida especialmente preparada para ellos.

\section{Sobre el origen del hetzmek}

El hetzmek es un ritual doméstico que es practicado en la actualidad, principalmente pero no exclusivamente, por la población de ascendencia indígena y campesina de Yucatán. Sin embargo, esta ceremonia no es privativa de Yucatán; además de celebrarse en Quintana Roo y Belice, donde recibe el mismo nombre, se realiza con otros nombres en otros estados del país y por otros grupos étnicos. Los lacandones que habitan las tierras bajas de Chiapas realizan una ceremonia que llaman mekik utiar. Este término, al igual que el hetzmek, se traduce como "llevar la criatura a horcajadas sobre la cadera". Además, según Villa Rojas, se realiza con los mismos propósitos que éste. En sus notas de campo, Philip Baer expresa que los lacandones le conceden tal importancia a este rito que constituye un requisito imprescindible para poder casarse (Villa Rojas, 1995: 303-304). ${ }^{8}$ Los chontales de la costa de Tabasco realizan una ceremonia muy similar al hetzmek de los mayas yucatecos y quintanarroenses, y al mekik-utiar

\footnotetext{
${ }^{8}$ Es importante señalar que Marion (1994), quien describe y analiza dos ceremonias similares al hetzmek entre los lacandones, el mek'bir de los lacandones meridionales y el mek'chahar de los lacandones septentrionales, y las compara con ésta, no menciona al mekik utiar.
} 
de los lacandones, que además persigue los mismos propósitos de éstas. Pero ellos llaman a su ceremonia xeke-meke. Si bien esta ceremonia no es privativa de Yucatán, Marion advierte que sí lo es de los grupos mayenses. Según ella, en la literatura etnológica disponible no se ha reportado una ceremonia parecida en algún grupo no mayense (Marion, 1994: 39).

En relación con el xeke-meke, Villa Rojas (1995: 363-364 y 440) dice explícitamente que su origen es prehispánico, mientras que en otros textos implícitamente asume también el origen prehispánico del hetzmek (Villa Rojas, 1971).

Además de Villa Rojas, otros autores de reconocido prestigio internacional, como Robert Redfield, Sylvanus Morley y Alberto Ruz Lhuillier, también asumen que el hetzmek es de origen prehispánico. Redfield dice que es "un rito de tránsito, pagano y preexistente" al bautismo cristiano (1944: 267); Morley, que "trae su origen desde tiempos antiguos" (1974: 180) y, en un recuento de los rasgos culturales que los mayas de Yucatán han logrado conservar a lo largo de los siglos, Ruz Lhuillier dice que es un rito que se ha conservado por tradición oral (1957: 67-68). Sin embargo, a pesar de sus afirmaciones y asunciones, ninguno de estos autores proporcionan las fuentes iconográficas, arqueológicas o documentales de esta presunción, como sí lo hacen en relación con otras manifestaciones culturales de los mayas que ellos analizan; tal es el caso de otros ritos asociados al ciclo de vida, los cuales están documentados en la Relación de las cosas de Yucatán, escrito por fray Diego de Landa. Los estudiosos de la cultura maya, entre ellos los mencionados arriba, continuamente hacen referencia a este texto y a códices mayas cuando sus afirmaciones pueden constatarse en esos documentos. Este es el caso de Mercedes de la Garza (1998:183), quien al describir los ritos asociados al parto, para apoyar sus afirmaciones dice: "hay representaciones de ambas ceremonias en el Códice Madrid".

Por otro lado, es importante señalar que quienes estudian los ritos de paso prehispánicos con base en fuentes documentales coloniales, no mencionan para nada al hetzmek. Al respecto pueden consultarse los trabajos de Enrique Bonavides (1992), Marie Odile Marion Singer (1994) y Mercedes de la Garza (1998).

Entonces, ¿en qué basan los mencionados autores la presunción y/o la afirmación de que el hetzmek es un rito de origen prehispánico? Utilizando como modelo de análisis el continuo rural urbano, Robert Redfield (1944) hace esta inferencia a partir de la creciente disminución en su importancia, en la frecuencia de su práctica y en su complejidad, conforme se pasa de los pueblos más aislados a las villas y a las ciudades. Este autor supone que las manifestaciones culturales de las poblaciones más aisladas y alejadas de los principales centros urbanos tienen prácticas culturales más cercanas a la forma en que las llevaban a cabo los antiguos mayas.

Retomando este mismo modelo de análisis, Villa Rojas adopta la misma suposición. Con base en ella, hace el recuento de las variaciones y permanencias que, en el momento de su investigación, habían sufrido diferentes expresiones de la cultura y la lengua de los mayas de Yucatán con relación a los patrones 
culturales que supone tenían los antiguos mayas. Desde esta perspectiva, el autor afirma que una de las áreas en la que puede notarse mayores diferencias entre los patrones culturales antiguos y los modernos es en relación con el ciclo de vida. Una de esas prácticas es el ritual del hetzmek, del cual dice que "ya va quedando como cosa del pasado en las comunidades menos aisladas" (Villa Rojas, 1971: 373). En un texto posterior, ${ }^{9}$ este autor siguió utilizando el mismo enfoque teórico y metodológico de análisis, pero advierte que, después de los años transcurridos desde la conquista española, las manifestaciones culturales actuales no son copia exacta del patrón prehispánico, ni de las formas de vida europeas; son "sistemas culturales híbridos, bien integrados y coherentes" (Villa Rojas 1968: 121).

Desde una perspectiva teórica y metodológica diferente de la de Redfield y Villa Rojas (1962), Marie-Odile Marion (1994) intenta demostrar que el ritual del hetzmek es de origen prehispánico; más exactamente, lo que esta estudiosa de la cultura maya afirma es que el hetzmek es una variante contemporánea de un rito prehispánico: el ka'put zihil, el cual describe Diego de Landa en su memorable texto Relación de las cosas de Yucatán. Como prueba de este origen analiza los elementos simbólicos de ambos rituales y los compara con los elementos simbólicos de otros dos rituales contemporáneos, el mek'bir y el mek'chahar, que practican los lacandones de Chiapas.

De la comparación de esos cuatro rituales (hetzmek, mek'bir, mek'chahar y ka'put zihil), ${ }^{10}$ Marion encuentra que todos comparten "rasgos estructurales de profundo significado", esto la lleva a proponer que los tres primeros son distintas derivaciones actuales del ritual prehispánico descrito por Landa. Además, afirma que estas coincidencias sugieren "un origen común lejano o bien la ocupación remota de un territorio vecino o cercano" entre ambos grupos mayas (Marion, 1994: 39).

En esta última idea Marion coincide con Villa Rojas, quien afirma que los lacandones actuales de Chiapas descienden de los mayas yucatecos; concretamente Villa Rojas dice que proceden de los antiguos quejaches, una tribu maya que hasta el siglo xvi habitó la parte sur del actual estado de Campeche y el Petén. Ante la conquista española y los intentos de catequización por parte de los religiosos, los miembros de esta tribu se fueron internando a zonas menos accesibles: a la selva. Este autor concede a Thompson el mérito de haber hecho tal descubrimiento (Villa Rojas, 1995: 257, 447 y460). ${ }^{11}$

Marion considera que los rituales contemporáneos son variantes y manifestaciones actuales del rito prehispánico porque comparten la permanencia de los

\footnotetext{
${ }^{9}$ La primera edición del texto anteriormente citado fue en 1964.

${ }^{10}$ Para conocer cómo se realiza el rito de mek' chahar entre los lacandones septentrionales y el mek'bir entre los lacandones meridionales, consultar Marion, 1994.

11 Villa Rojas (1995: 460) advierte que los antiguos pobladores de la región que hoy habitan los lacandones, estuvo habitado en el siglo xv por otro grupo étnico que hablaba chol y que también fueron llamados lacandones por el hecho de que el pueblo en el que habitaban se llamaba Lacam-tun. Pero éstos fueron desapareciendo.
} 
siguientes elementos invariantes: 1) Los tres rituales contemporáneos inician con el levantamiento de los niños de su hamaca, lo cual indica simbólicamente un "nacer de nuevo"; además la autora afirma que según Landa y el Diccionario Maya Cordemex, el término Ka'put zihil se traduce de igual modo. 2) Marcan el inicio de los niños en las actividades y responsabilidades de los adultos según su sexo, y por esta vía, el paso de la niñez a la edad adulta. 3) Uno de sus objetivos es enseñar a los niños a comportarse de acuerdo con las normas y costumbres de su sociedad. Según Marion, estos elementos son clave para identificarlos como el mismo ritual modificado históricamente, de acuerdo con las condiciones particulares de cada sociedad que lo practica.

A pesar de los elementos que comparten los rituales contemporáneos entre sí, y con el ritual prehispánico, nos parece que las coincidencias no son comunes a los cuatro rituales, sino que cada uno comparte unos elementos con alguno o algunos de ellos, y otros elementos con los demás. Por otra parte, las coincidencias obedecen más que nada a que en conjunto expresan concepciones, costumbres y normas de sociedades que tuvieron un origen común o que convivieron durante un tiempo (remoto). Pues como la misma Marion manifiesta, son elementos que también están presentes en otro tipo de rituales, como los agrícolas. De modo que las coincidencias mencionadas por Marion no demuestran necesariamente que los rituales contemporáneos deriven del prehispánico. (Para conocer las coincidencias y diferencias entre estos cuatro rituales, según las descripciones que de ellos hace Marion, véase el cuadro 1 al final del trabajo).

El hecho de que el hetzmek y el mek'bir se practiquen cuando el bebé tiene escasos meses de nacido, y el ka'put zihil y el mek'chahar, al inicio de la adolescencia, indica que se trata de rituales de paso distintos con objetivos diferentes.

Nos parece que, por los elementos que integraban el ka'put zihil y la edad a la que éste se realizaba, fue más que nada un rito de pubertad, como lo es hoy día el mek'chahar. Por lo que describen Diego de Landa (1978), Enrique Bonavides (1992: 411), Mercedes de la Garza (1998: 183), y la misma Marie-Odile Marion, los elementos que conforman el ka'put zihil indican que estaban dirigidos a otorgar otro estatus social a los adolescentes en la comunidad; a señalar que ya estaban en la posibilidad de casarse, y a indicarles las responsabilidades que debían cumplir a partir de entonces. Por eso, el ka'put zihil fue un requisito indispensable para contraer matrimonio, como lo es hoy el mek'chahar. En cambio, el ritual del hetzmek, como el mek'bir, marca la ampliación del espacio de interacción del bebé; es su entrada a la comunidad para iniciar un proceso de sociabilidad y socialización más amplio que el de su propia familia; sirve para indicar que se trata de un individuo apto para constituirse en miembro de la comunidad, que deberá ser tratado y socializado según su sexo, informado simbólicamente a los asistentes en la ceremonia ritual.

A diferencia de la propuesta de Marion, Enrique Bonavides (1992) y Mercedes de la Garza (1998), quienes abordan los ritos de paso de los mayas prehispánicos desde el nacimiento, no mencionan el hetzmek entre éstos y consideran el 
caputzihil, del que habla Landa, un ritual de pubertad. De la Garza habla de tres rituales de la infancia: el entablillado de la cabeza a los cuatro o cinco días de nacido; la colocación de una cuenta blanca en la coronilla a los niños y una concha roja sobre el pubis a las niñas, cuando tienen tres años de edad; el caputzihil o rito de la pubertad, que se realizaba cuando niños y niñas tenían trece años de edad. Durante esta última ceremonia se les retiraba la cuenta blanca y la concha roja respectivamente.

Una propuesta interesante es la de Carmen Romero de Nieto (1986). Ella vincula el actual rito del hetzmek con la antigua práctica de los mayas prehispánicos de consultar con un adivino o sacerdote del calendario (el $a h-k$ 'in o los chilames) para que, de acuerdo con el día y hora del nacimiento del bebé en el calendario ritual o tzolk'in, asignara el nombre que llevaría en la infancia ${ }^{12}$ y adivinara el destino que le correspondería. Como parte de este destino se le asignaba un oficio (Romero, 1986: 20 y 35). Actualmente, dice Romero de Nieto (1986: 38-39), el hetzmek ha perdido, entre otros elementos, a su celebrante, y ha pasado de ser un acto profundamente religioso a ser un rito de naturaleza mágica.

Romero hace la propuesta anterior a partir de la manera como interpreta la siguiente afirmación de Sylvanus Morley. Este célebre mayista, después de describir sintéticamente la ceremonia moderna del hetzmek, asienta que "en la época antigua, el niño era llevado ante un sacerdote, quien hacía su horóscopo y daba al niño el nombre que debía llevar durante la niñez" (Morley, 1975: 180). Si bien Morley no dice explícitamente que el hetzmek sea una versión moderna de la antigua ceremonia de adivinación y de imposición de nombre, el hecho de hacer la afirmación que reproducimos arriba, después de hablar del hetzmek, da lugar a la interpretación que hace Romero. Para apoyar su idea y ampliar la información que proporciona Morley, esta autora cita igualmente a Landa cuando éste refiere que la consulta al sacerdote, "para que les viese el hado y dijese el oficio que habían de tener y pusiese el nombre que había de llevar el tiempo de su niñez", se realizaba después que concluía el proceso de deformación craneana, la cual duraba varios días (Landa, 1978: 58). ${ }^{13}$ Con la cita de Landa, Romero únicamente demuestra la existencia prehispánica de esta última práctica ritual, no del hetzmek.

Por otra parte, la información etnográfica que proporciona Villa Rojas sobre los mayas que habitan el cacicazgo de X-Cacal, Quintana Roo, contradice la hipótesis de Romero. Villa Rojas (1995: 164) describe el procedimiento de asignación de nombre a los recién nacidos de este grupo étnico durante los años de 1935 y 1936, periodo en el cual hizo su investigación de campo. Este autor afirma que

${ }^{12}$ Según Bonavides (1992: 408-410), los infantes llevan el nombre impuesto en este ritual hasta antes de la ceremonia del caputzihil; después de esta ceremonia empiezan a llevar el nombre de su padre. También dice que mediante la imposición de un nombre se le confiere al infante una personalidad o alma y que el nombre conecta al nin̄o "con su ascendencia divina y humana, a la vez que recibe un lugar en la sociedad".

${ }^{13}$ Garza (1998:183) y Bonavides (1992: 408) también mencionan esta práctica ritual. 
cada vez que un niño nacía, su padrino, previamente seleccionado por los padres del niño, acudía a la cabecera o Pueblo Santo para que el escriba que allí radicaba le informara el nombre que le correspondía al recién nacido en un santoral impreso en la ciudad de Mérida, según la hora y día de su nacimiento. Meses después de la imposición de nombre, los mayas de Quintana Roo celebraban el rito de hetzmek a sus hijos. Entonces, esta información etnográfica parece indicar que el procedimiento antes mencionado y no el hetzmek era la derivación de la antigua práctica de imposición de nombre a las criaturas por parte de un chilam con base en el tzolk'in.

Por último, queremos mencionar el trabajo de Dolores Cervera, quien afirma que el ritual del hetzmek "evoca el génesis maya" prehispánico (2006: 1 y 16). Nos parece que aunque esta autora no dice explícitamente que el hetzmek tiene un origen prehispánico, su afirmación anterior lo sugiere. En efecto, ella interpreta los distintos elementos que constituyen este ritual y las acciones simbólicas que ocurren en su celebración, como expresiones de la cosmovisión maya prehispánica. Para ello utiliza una cosmovisión, que ha sido reconstruida por varios estudiosos de la cultura maya ancestral a partir de fuentes diversas: datos arqueológicos, códices mayas, documentos coloniales, y estudios etnográficos contemporáneos sobre diversos grupos que habitan en la llamada área maya, y sobre otros pueblos mesoamericanos. Con base en esta cosmovisión maya se interpretan los elementos rituales contemporáneos, asumiéndolos como supervivencias de esa cosmovisión.

En el apartado 5 de este trabajo continuaremos describiendo y analizando cómo Cervera hace esta interpretación de los elementos del hetzmek a partir de la cosmovisión maya. Por ahora sólo queremos decir que, aun cuando efectivamente el ritual del hetzmek expresara concepciones del mundo de los mayas yucatecos prehispánicos, no puede deducirse de esto su existencia prehispánica. Bien podría tratarse de una invención posterior como producto de la adopción de creencias y modos de comportamiento ajenos a la cultura maya, recreados a partir de ésta. Eric Thompson, uno de los primeros especialistas en el estudio de la cultura y la religión maya prehispánica a partir de fuentes diversas, advierte de los peligros que puede acarrear el uso descuidado de estas fuentes. Recomienda, además, que es necesario tener "algún conocimiento de las costumbres y tradiciones españolas del medievo" porque "se han atribuido a los mayas ritos modernos que proceden de las usanzas españolas" (Thompson, 1979: 4-5). Previamente, en 1941, Redfield hizo la misma observación al mencionar la dificultad de distinguir entre la "cultura española de los invasores" y la "cultura india de los nativos", dado que en "el transcurso de cuatro siglos de interacción han tendido a producir lo que puede considerarse como invenciones nuevas y el desarrollo de una nueva cultura" (Redfield, 1944: 116-117). Ésta es una importante llamada de atención, ya que también nos ha parecido que algunos estudiosos igualan, con mucha facilidad, las prácticas de larga raigambre con la cultura maya ancestral, olvidando que los mayas actuales son producto de la imbricación de dos cultu- 
ras, la maya y la española del siglo xvı, así como su progresiva articulación y desarrollo a partir de entonces, a lo que hay que agregar las influencias culturales posteriores, es decir, la cultura contemporánea con importantes ingredientes de la cultura norteamericana.

Aunque las propuestas de Redfield y Villa Rojas, de Marion y de Cervera, derivadas de distintos análisis teóricos y metodológicos, podrían ser plausibles y podrían llegar a corroborarse, aquí queremos dejar constancia de que el origen prehispánico atribuido al ritual del hetzmek es una inferencia teórica, no un dato empírico. ${ }^{14}$

\section{Problemáticas teóricas vinculadas al análisis del hetzmek}

Continuando con el recuento de los estudios que hasta el momento se han hecho sobre el hetzmek, consideramos importante incluir el análisis en cuanto al porqué y al cómo lo han abordado quienes se han ocupado de este ritual. Es decir, ¿lo han tomado como objeto específico de estudio o como parte de una temática más amplia? ¿Con qué finalidad lo han descrito y analizado? ¿Cuáles son las problemáticas teóricas y sociales en las que se ha insertado su estudio?

En relación con la primera pregunta podemos decir que, de una u otra manera, la mayoría de los investigadores interesados en la cultura maya han dedicado algunas líneas para referirse al hetzmek. Algunos lo han hecho de manera extensa y otros en forma mucho más sintética, con el propósito de registrar la pervivencia de una ceremonia a la que, según hemos visto, le atribuyen un origen prehispánico. Pero unos y otros se han aproximado al hetzmek de manera secundaria; es decir, no constituye el tema central de sus escritos. Entre éstos podemos mencionar los trabajos de: Patricia Fortuny (2004), Carlos R. Kirk (1982), Sylvanus Morley (1974), Ella Fanny Quintal et al. (2003), Robert Redfield (1944), Robert Redfield y Alfonso Villa Rojas (1962), Eric Thompson (1979), Richard Thompson (1974), Alfonso Villa Rojas (1968; 1971; 1978; 1995), y otros más.

Morley, Redfield y Villa Rojas lo abordan como parte de amplios estudios de la cultura maya yucateca, peninsular y del área maya en general. Eric Thompson, como un ejemplo de magia imitativa, y esta última como una práctica común en Mesoamérica. Fortuny utiliza la posición en la que se abraza al niño en el ritual del hetzmek como metáfora de la situación de los migrantes mayas yucatecos en

\footnotetext{
${ }^{14}$ No queremos dejar de mencionar que cuando este trabajo fue presentado como ponencia en el Séptimo Congreso Internacional de Mayistas, la arqueóloga Sylviane Boucher nos señaló que en la cerámica encontrada en Calakmul hay representaciones de mujeres con niños a horcajadas. Si bien éste es un dato importante, por el momento solamente indica una manera de abrazar a niños pequeños y no necesariamente la celebración de un ritual. Marion hace una afirmación similar cuando dice que los huastecos acostumbran cargar a sus hijos a horcajadas antes de que aprendan a caminar. Pero, según la literatura etnológica, no realizan una ceremonia similar a la del hetzmek la primera vez que se abraza a los niños de esta manera (Marion, 1994: 39).
} 
los Estados Unidos, los cuales tienen un pie en este país y el otro en Yucatán; pero también ve la celebración del ritual en los Estados Unidos por parte de los migrantes yucatecos como pervivencia de una tradición y como reforzamiento y autovaloración de la identidad étnica de origen. Kirk, Quintal et al., y Richard Thompson lo abordan como parte de su análisis del compadrazgo y más ampliamente de la organización social de la población maya yucateca. Éstos son los temas y las problemáticas en las que los autores anteriores insertan la descripción y análisis del ritual del hetzmek, lo cual no significa que se limiten a ellos. Ciertamente proporcionan información e interpretaciones que nos parecen útiles para análisis posteriores. De esto hablaremos en el siguiente apartado.

Marie Odile Marion (1994), Hilaria Máas Collí (1983; 1986) y Alicia Peón (2000) han estudiado el hetzmek como un elemento central en su descripción y análisis, pero igualmente lo han insertado como parte de una investigación más amplia.

Marion se ocupa de este ritual en tanto uno más de los rituales indígenas en general. Ella analiza estos rituales buscando conocer, mediante su estructura y simbolismo, la mentalidad, las concepciones y las creencias de sus practicantes. Este mundo subjetivo e intersubjetivo, y su objetivación en rituales, permiten identificar a los grupos étnicos, su continuidad y reproducción a lo largo del tiempo. En este sentido podemos decir que el hetzmek no es sólo una pervivencia, una práctica en proceso de desaparición, sino también una vía de reproducción social y cultural, y de reafirmación de la pertenencia social y étnica.

Máas (1983) y Peón (2000), por su parte, describen y analizan el hetzmek como uno de los rituales asociados al ciclo de vida, y lo definen como rito de paso o de iniciación. Varios de los autores arriba mencionados hacen esta misma afirmación. Aunque Máas y Peón describen la estructura, los componentes y los participantes en el hetzmek, e interpretan algunos de sus elementos como expresión de la cosmovisión maya, se centran más que nada en la función del ritual como medio de transmisión cultural, ${ }^{15}$ como mecanismo de introducción de los niños a la comunidad o al grupo étnico.

En la revisión bibliográfica que hemos realizado, solamente hemos encontrado dos trabajos cuyo objeto específico de estudio es el hetzmek; una publicación de Carmen Romero de Nieto (1986) y una ponencia de María Dolores Cervera (2006).

Romero describe, compara y analiza seis rituales de hetzmek realizados en el oriente del estado de Yucatán, que ella observó directamente. Como producto de su análisis sostiene que a pesar de las diferencias observadas en su realización, lo esencial permanece inalterable. Opina que los elementos inalterables simbolizan, en un plano amplio y cósmico, las concepciones mayas sobre el tiempo, el espacio y las deidades; en un plano más cercano y terrenal, simbolizan las

\footnotetext{
${ }^{15}$ Máas prefiere hablar de endoculturación, mientras Peón de socialización, pero se ocupan más que nada de la transmisión cultural. Con relación a la comparación y discusión entre los conceptos de socialización y endoculturación, y su relación con la transmisión cultural, puede consultarse el trabajo de Villanueva, 2004.
} 
cuestiones prácticas asociadas a la vida cotidiana y al ciclo de vida. Por lo tanto, a partir de los elementos que proporciona el texto de Romero, podemos decir que la ceremonia del hetzmek vincula el lugar de los infantes en el cosmos y en la sociedad maya; asigna un lugar a los sujetos en ambos planos.

Cervera, por su parte, como el título de su texto dice, se propone analizar la celebración del hetzmek en tanto expresión simbólica de la construcción de los niños como personas y, en este sentido, de las prácticas de crianza. Estas prácticas de crianza, y su representación simbólica en el hetzmek, nos señala, son resultado de las etnoteorías parentales de los mayas de Yucatán. Con este concepto, la autora se refiere a las nociones nativas sobre la infancia y el desarrollo de los niños, y las nociones sobre el papel de los padres y los propios niños en ese proceso. Según Cervera, en la mentalidad de los mayas de Yucatán, los niños todavía no son personas al nacer; obtienen esta categoría a lo largo de su vida, a través del desarrollo, generado y apoyado con la intervención de los adultos y de los mismos niños. La celebración del hetzmek marca el inicio de este proceso.

Pero la celebración del hetzmek, advierte Cervera, también expresa la cosmovisión maya; "evoca la génesis maya". A partir de ambos supuestos, utiliza los conocimientos previos en ambos campos, la cosmovisión maya y las etnoteorías parentales de los mayas de Yucatán, para interpretar los elementos de este ritual. En el siguiente apartado analizaremos cómo hace esta interpretación.

Tomando todos estos textos en conjunto podemos decir que, en mayor o menor medida, el hetzmek ha sido estudiado en relación con los siguientes temas y problemáticas: pervivencia de prácticas ancestrales en el mundo contemporáneo; simbolización de elementos de la cosmovisión maya para transmitirla a los participantes, y así reproducir la cultura; introducción formal de los infantes a la sociedad; transmisión cultural de las normas y valores de la vida cotidiana; creación y/o reforzamiento de lazos de parentesco (compadrazgo); simbolización de concepciones sobre la infancia; mecanismo para la conversión de un ser en persona; asignación de una identidad personal en el entramado social.

\section{Funciones y propósitos atribuidos al hetzmek}

Para conocer las funciones y propósitos que los practicantes le atribuyen al hetz$m e k$, y las funciones que cumple aunque sean desconocidas para éstos, los estudiosos se han basado en la exégesis nativa y en sus propias interpretaciones como observadores y analistas externos. Unos se apoyan más en la primera, otros en la segunda; pero ocasionalmente no resulta muy claro el fundamento de las afirmaciones.

En cuanto a la exégesis nativa, de las afirmaciones de los padres puede deducirse que con la celebración del hetzmek ellos buscan incentivar, favorecer, el desarrollo de las habilidades físicas e intelectuales de sus hijos. La apertura de las piernas durante la ceremonia, y desde entonces a partir de ella, hace que los 
niños lleguen a ser buenos caminantes. La mayoría de los autores que han descrito y analizado este ritual coinciden con esta exégesis. Igualmente coincide con la información que cada una de nosotras ha obtenido en nuestras particulares investigaciones de campo. En Tahmek, Yucatán, una informante dijo: "Se hace antes de que quede duro sus pies. Es para que caminen rápido" (Diario de campo, 18 de diciembre de 2000: 652). Otro informante manifestó: "Me dijeron que esto se hace para que aprendan a caminar pronto y para que sean diestros en el trabajo. Eso oí de mis mayores". Don Sebastián habla como si él no estuviera convencido de la efectividad de la ceremonia (Diario de campo, 20 de diciembre de 2000: 657).

Con los alimentos que la madrina o el padrino le dan a probar al infante durante la ceremonia, se intenta contribuir al desarrollo de sus habilidades mentales, tanto para memorizar como para razonar, para abrir el entendimiento y para tener discernimiento. Esta intención se expresa en las oraciones que la madrina le dice al infante mientras ejecuta esas acciones.

Máas Collí (1986: 8) reproduce estas oraciones en su descripción de la manera como acostumbra celebrarse el hetzmek en Chemax, Yucatán:

\footnotetext{
"Haant le he'a utia'al ka'ah he'epahak a na'at" (come este huevo para que brote tu entendimiento).

"Haant le xtóop'a'utia'al ka'ah tóop'ok a tuukul" (come esta pepita gruesa para que brote tu inteligencia y seas capaz de razonar).

"Haant le k'aha' utia'al ka'ah k'a'ahak a wiik" (come este pinole para que tengas buena memoria; seas una persona reflexiva, razonable y recapacites tu conducta).

"Haant le ta'aba' utia'al ma' a táabasa'al" (come esta sal para que no seas engañado).
}

Según la interpretación que hace Máas de la correlación entre los alimentos ofrecidos y las oraciones enunciadas, los primeros han sido elegidos, no por sus cualidades intrínsecas, sino porque su nombre en maya rima con el nombre también en maya de las capacidades que se quiere favorecer, desarrollar o despertar. Así, hé (huevo) rima fonéticamente con he'epahal (abrir), y se usa simbólicamente para abrir o para hacer brotar el entendimiento. Xtóop (pepita gruesa) rima con tóop'ol (brotar), y se utiliza para hacer brotar la inteligencia y la capacidad de razonar. $K^{\prime} a h$ (pinole) con sonido parecido a k'a'ahal (recordar) se usa para tener buena memoria, ser reflexivo y razonable en su conducta. Ta'ap (sal) suena similar a táabsah (engañar), para que no sea engañado.

Antes de Máas Collí, Villa Rojas hizo registros similares y estableció relaciones de semejanza fonética entre el nombre en maya de los alimentos usados en el ritual del hetzmek y el nombre de las cualidades que se pretende desarrollar en los niños con ellos. Sin embargo, en su redacción no queda claro si las frases entrecomilladas son expresadas por la madrina del ritual y traducidas al español por él, o son sus interpretaciones. Las descripciones de Máas Collí nos permiten entender que se trata de lo primero. Así, Villa Rojas (1978: 414) dice: 
la madrina le fue dando para probar de cada comestible ofrendado: el huevo, cuyo nombre (hê) significa también "abrir", "para abrirle o despertarle el entendimiento"; la chaya (del maya chay, fonéticamente semejante a xay que significa "división en dos partes") "para bifurcarle el pensamiento, de modo que se sepa apreciar el pro y el contra de cada cosa"; el "pinole (kah, semejante de kahal que significa 'recordar') para dotarlo de buena memoria"; finalmente, las pepitas de calabaza (topp, semejante de tóppol "abrirse las flores y florecer") "para hacerle florecer la inteligencia".

La única diferencia que podemos notar en cuanto a los alimentos que se ofrecen a los niños durante la celebración del hetzmek en Chemax, Yucatán y X-Cacal, Quintana Roo, es que en el primer pueblo no se ofrece chaya sino sal.

Creemos que es muy probable que esos alimentos no solamente se usen por su semejanza fonética con términos en maya, los cuales expresan las cualidades que los adultos pretenden despertar, favorecer o potenciar en los niños, sino también por las cualidades esenciales que los practicantes del ritual les atribuyen, o por lo que esas cualidades intrínsecas representan simbólicamente. Entonces se utilizan para adquirir esas cualidades. Por ejemplo, Romero (1986: 31) asienta que algunos informantes le dijeron que el huevo se usa porque representa vida y fertilidad, y con él se pretende "augurar una buena acción procreadora". Sería necesario profundizar en el análisis de las cualidades que los adultos nativos atribuyen a esos alimentos para derivar de ellas la razón de su utilización en el ritual del hetzmek.

En términos generales, la validez de las interpretaciones arriba mencionadas sobre el propósito del hetzmek se fundamentan en el hecho de que a los niños que no demuestran ser hábiles o son flojos para caminar, o que parecen tontos para razonar e incapaces para aprender, los adultos les dicen: "parece que no te hicieron hetzmek" (Máas Collí, 1983: 57). A Virginia Prieto, una de las autoras de este trabajo, cuando no podía entender alguna explicación dada por los informantes, o cuando fingía no entender buscando respuestas más precisas y explícitas, le dijeron: "no puedes entender porque no te han hecho hetzmek". Lo mismo ocurrió cuando se mostró incompetente como madrina del hetzmek de Julia.

Por lo anterior podemos decir que los padres realizan el ritual del hetzmek a sus hijos porque consideran que la simple transmisión cultural será insuficiente si no lo preparan anímica, física y mentalmente para adquirir los conocimientos y las habilidades. Posiblemente, con estos actos, simbólicos y mágicos desde nuestra perspectiva de intérpretes externos, traten de conjuntar las fuerzas y condiciones favorecedoras de ese proceso.

Siguiendo con la exégesis nativa, los padres también dicen que la ceremonia del hetzmek debe realizarse a los tres meses de edad en el caso de una niña, y a los cuatro meses de edad, en el caso de los niños. La razón que dan quienes saben esta información es que los principales instrumentos o medios en los que desarrollarán su trabajo las niñas (el fogón en el cual ponen a cocer los alimen- 
tos, la banqueta donde tortean, y el banquillo en el que se sientan a tortear) tienen tres piedras el primero, y tres patas la segunda y el tercero. En cambio, el espacio en el que los niños sembrarán su milpa, tiene cuatro esquinas.

Los especialistas en religión y cosmovisión maya opinan al respecto que el tres es un número femenino, asociado a la mujer, y el cuatro es un número masculino, asociado al hombre (Marion, 1994: 28-29). Quintal et al. (2003: 311) relacionan estas diferencias de edades en la celebración del hetzmek con el hecho biológico de la diferencia en la velocidad de maduración entre los sexos; las niñas maduran más pronto que los niños. Nos parece que las tres explicaciones, la exégesis nativa de la naturaleza sociocultural, la cosmológica y la biológica, pueden ser complementarias. Pero mientras la primera forma parte de un saber explícito de la conciencia discursiva, la segunda es desconocida, es parte del saber inconsciente, y la tercera podría ser inconsciente o podría ser parte de la conciencia práctica. ${ }^{16}$

Nos ocuparemos ahora de las interpretaciones que los distintos estudiosos han hecho del hetzmek con base en los elementos que lo conforman, su estructura y secuencia, la etapa de la vida en la que lo realizan, y la situación del niño antes y después de su celebración.

La mayoría de los autores que hemos revisado, si no todos, concuerdan en que el hetzmek constituye un rito de paso y de iniciación a otra etapa de la vida de los infantes. Simultáneamente es la presentación formal y la introducción simbólica del niño a la sociedad a la que pertenecen sus padres. En efecto, la secuencia de pasos que se sigue en la celebración de este ritual, y los elementos de los que consta (objetos, símbolos y el discurso que los padrinos dirigen a los niños en el transcurso), así lo indican.

La colocación de instrumentos de trabajo en las manos de los infantes según su sexo, indica simbólicamente las actividades económicas que los padres y padrinos esperan que el niño o la niña realicen cuando sean adultos. Estas expectativas se generan a partir de la posición y situación de los padres en la estructura social del grupo. Esta perspectiva de análisis es enfatizada sobre todo por aquellos investigadores que estudian el hetzmek en el marco de los rituales del ciclo de vida y como mecanismo de transmisión cultural. Una inferencia plausible que en lo general es aceptable, pero queremos hacer dos precisiones.

Nos parece, igualmente, que debería considerarse que con la presentación de instrumentos de trabajo según el sexo también se está asignando al infante su identidad de género y, al mismo tiempo, comunicándola simbólicamente a

\footnotetext{
${ }^{16}$ En cuanto al saber y la conciencia que los actores tienen respecto a la fundamentación de sus actos, Giddens distingue entre la conciencia discursiva, la conciencia práctica y la inconciencia. La primera es aquello que sabemos, de lo que nos damos cuenta y que podemos expresar con palabras; la segunda es aquello que también sabemos y nos damos cuenta, pero que no podemos expresar con palabras; es simplemente el saber tácito, el saber hacer o el saber notar o distinguir; la inconciencia es aquello que no logra aflorar a la conciencia pero que está alojado en algún lugar muy profundo de nuestro cerebro, porque problemas psicológicos lo obstaculizan (Giddens, 1995: 24 y 42).
} 
los asistentes; a partir de entonces, éstos deberán tratarla como niña o como niño. Ésta es una propuesta que Nancy Villanueva (2004: 113) ya había expresado como producto de su investigación sobre procesos de socialización infantil en Tahmek, Yucatán. Apoyamos esta interpretación en la propuesta de Pierre Bourdieu (1991: 344), quien afirma que la primera y más fundamental partición del mundo es la de género, entre lo masculino y lo femenino. También la apoyamos en el hecho de que hasta el momento de la celebración del hetzmek, el infante ha permanecido en gran medida confinado al espacio doméstico, con escasos o nulos contactos con personas que no son miembros de la familia, como un mecanismo de protección a su salud. Por lo mismo, es posible que no muchos estén enterados del género del infante. En épocas más remotas, cuando niños y niñas vestían indistintamente el hipil que ahora llevan exclusivamente las niñas, aunque hoy día sean cada vez menos quienes lo usan, esta asignación de identidad de género mediante los instrumentos de trabajo debió jugar un papel más importante.

Aunque las dos asignaciones, la actividad económica y la identidad de género, están presentes en el ritual, y una apoya a la otra, con excepción de Quintal y otros (2003), los autores han enfatizado la asignación económica. Como ejemplo de este énfasis económico referimos al trabajo de Kirk (1982).

Por otra parte, la presentación de instrumentos de trabajo a los niños también marca el inicio, simbólico, del aprendizaje de estas actividades, e indica que su enseñanza deberá ser una responsabilidad compartida por padres y padrinos, sobre todo a falta de los primeros, ya sea por muerte o incapacidad.

Colateralmente, y como parte de la misma perspectiva de introducción del niño a la sociedad, y de transmisión cultural, algunos autores mencionan que en la ceremonia del hetzmek, mediante objetos y actos simbólicos, los padres y los padrinos transmiten a los niños y las niñas las normas, los valores y las actitudes que esperan asuman en su comportamiento futuro. En este sentido resultan interesantes los comentarios de Kirk (1982: 139 y 140). Según este autor, con los instrumentos de trabajo que los padrinos van poniendo sucesivamente en sus manos a sus ahijados, y con la comida que igualmente les dan a probar durante la ceremonia, se pretende que los niños aprendan a sobrevivir en el medio en el que les tocó nacer; conozcan y acepten "su rango y su papel" dentro de una sociedad más amplia, aprecien los alimentos que componen la dieta de los campesinos pobres, que se conformen y sean felices con ellos. En la ceremonia de hetzmek observada y relatada por Marion (1994: 26), también se expresa esta misma idea.

Resumiendo, podríamos decir que el hetzmek es una especie de investidura; una ceremonia en la que se comunica a los presentes que el sujeto presentado es un niño o una niña, y que en el futuro deberá ser tratado por los demás como tal; que en términos de su género le corresponderá desempeñar la actividad económica asignada a ese género en la sociedad a la que pertenecen. Fulanito es un $x y$ o una $x x$ por lo que deberá aprender a desempeñar la actividad que corresponde a un $x y$ o a una $x x$ en el grupo al que pertenecen sus padres, e igualmente deberá aprender a comportarse según la cultura que caracteriza a ese grupo. 
Al respecto, Kirk (1982: 135) sostiene que el hetzmek es una ceremonia orientada a la comunidad y a los familiares; pero creemos que igualmente está orientada al iniciado porque en el transcurso de ella se le van presentado objetos de trabajo y alimentos, que deberá aprender a usar y comer respectivamente, mientras la madrina o el padrino habla con él o ella. Afirmamos esto porque consideramos que la práctica del hetzmek representa igualmente el inicio del proceso de socialización infantil, de manera más sistemática y posiblemente intencional. Es posible, además, que los padres consideren que a la edad a la que se practica ese ritual, los niños ya hayan alcanzado la madurez mental y física necesaria para iniciar los aprendizajes.

En este sentido, concordamos con Marion (1994), Quintal et al. (2003) y Bracamonte y Lizama (2006), quienes han mencionado esa importante función práctica de la ceremonia de hetzmek: el inicio de la socialización y la sociabilidad. ${ }^{17}$ Esto es así por dos razones. 1) Durante la etapa previa, los pequeños han permanecido confinados al hogar doméstico porque pasan la mayor parte del tiempo durmiendo y comiendo y porque son físicamente débiles y vulnerables ante enfermedades como el "mal de ojo" y los "malos aires". Aunque esta vulnerabilidad continúa durante algunos años más, va disminuyendo paulatinamente. Además, los padres toman medidas preventivas, como colocarle objetos que contrarrestan esos males. 2) Una vez que el niño y la niña han alcanzado la edad suficiente para poder ser sostenidos a horcajadas sobre la cadera izquierda de su cargador, según la tradición de la población practicante de este ritual, su espacio social de interacción y el número de personas con quienes comenzarán a interactuar se irá incrementado. Esta postura aliviana la carga, de modo que niños tan pequeños como de seis años pueden cargar a sus hermanitos o hermanitas e introducirlos a sus juegos. De esta manera, los niños entrarán en contacto con nuevos aprendizajes en un sentido amplio (socialización); entre ellos, aquellos que tienen que ver con la capacidad y la disposición para interactuar y para comunicarse con los demás (sociabilidad). Quintal et al., para quienes el hetzmek marca el inicio de una segunda etapa de la vida de los pequeños (2003: 311), expresan esta idea de la siguiente manera:

Desde el día de su jéets méek' cualquier niño será cargado en la cadera y de esa forma acompañará a sus mayores en todas las actividades cotidianas en la casa, en el solar, en la milpa, en el pueblo y fuera de él. Dejará de permanecer largas horas en su hamaca para iniciar su largo proceso de socialización, observando a sus padres y hermanos, e imitándolos, siguiendo sus actitudes y ejemplos (2003: 312).

\footnotetext{
${ }^{17}$ Nosotras concebimos la sociabilidad como un aspecto de la socialización. Mientras la socialización es un amplio y complejo proceso de transmisión, percepción, interpretación, interiorización y aprendizaje de un conjunto de conocimientos y competencias, la sociabilidad abarca una de esas competencias y conocimientos: requiere que el individuo conozca las reglas del juego interactivo, prevea o calcule las reacciones de los otros a sus actos, tome decisiones y actúe sobre la base de sus cálculos (Villanueva, 2004: 39-42 y 232; Carrithers, 2001: 14500-14503).
} 
Alejándose de la exégesis nativa y de las interpretaciones prácticas y terrenales, como las que hemos expresado anteriormente, algunos autores han pretendido desentrañar las estructuras profundas del ritual, sus significados, en general desconocidos por los propios actores, interpretando el simbolismo expresado en los componentes del ritual (acciones y objetos). Lo han hecho relacionando estos componentes con los elementos que integran la cosmovisión maya prehispánica. Se refieren a una cosmovisión reconstruida inicialmente por Sylvannus Morley (1946) y Eric S. Thompson (1963) con base en datos arqueológicos, iconográficos, jeroglíficos, códices mayas y documentos coloniales, y posteriormente desarrollada, entre otros especialistas, por Linda Schele y David Freidel (Florescano, 1999: 61-62).

La mayoría de los autores que se ocupan de este asunto en su análisis del ritual del hetzmek, interpretan el número de vueltas, que los padrinos dan a la mesa en la que se colocan las comidas y los utensilios de trabajo, y los sentidos en los que se inician y concluyen, utilizando esa cosmovisión.

Respecto al número de vueltas, los autores mencionan que se dan nueve, si se trata de una niña, y trece si se trata de un niño, porque el nueve es un número femenino y el trece masculino. Esta correlación obedece a que en la cosmovisión maya el inframundo (la tierra) asocia a la mujer y a las características femeninas, y tiene nueve capas; el supramundo (el cielo) corresponde al hombre y todo lo masculino, y tiene trece capas. Ya desde 1945 Morley había establecido esa correlación entre el número, el género de los sujetos y la cosmogonía maya, al tratar de explicar por qué entre los mayas del siglo xvı los hombres se producían trece sangrías y las mujeres nueve como remedio para el dolor de muelas (Morley, 1974: 195). Romero (1986: 27-28) y Cervera (2006: 15) retoman esta correlación para afirmar que en los rituales del hetzmek se reproduce la cosmovisión maya. ${ }^{18}$ Pero Cervera menciona que en general toma estas ideas, y la que expongo a continuación, de la interpretación del ritual del hetzmek y otras ceremonias que hace John Sosa (1985) como producto de su investigación en Popolá, Yucatán.

Cervera dice que las direcciones inversas en las que se realizan las dos series de vueltas, primero en sentido contrario a las manecillas del reloj y posteriormente siguiendo el sentido de éstas, tienen el propósito de "delimitar o atar el espacio ritual y abrir un camino entre la tierra y las direcciones del cosmos para establecer un espacio de comunicación con los seres extramundanos que ahí residen" (2006: 14-15). También dice que el sentido del primer recorrido reproduce el recorrido solar en la bóveda celeste porque inicia en el Este, desde donde se dirige hacia el Norte y, después de recorrer todos los puntos cardinales "finaliza en el centro". No nos dice qué otra función tendría la segunda serie de vueltas, en el sentido de las manecillas del reloj (partiendo del Este en dirección al Sur hasta llegar de nuevo al Este), además de la de deshacer el espacio ritual.

\footnotetext{
${ }^{18}$ Este tipo de clasificaciones del mundo (cielo-tierra) y sus asociaciones con el hombre y la mujer respectivamente, no son privativos de los mayas; parecen estar presentes en las cosmovisiones de muchos grupos étnicos. Bourdieu establece asociaciones similares cuando analiza las concepciones y prácticas rituales de los argelinos (1991).
} 
Los mayas antiguos acostumbraban delimitar y santiguar sus espacios rituales antes de celebrar las ceremonias. Según el relato de fray Diego de Landa, en el caso del ka'put zihil, al que nos referimos en el apartado 3, hacían esto colocando cuatro banquillos en las cuatro esquinas del patio donde se realizaba el ritual; en cada uno de estos banquillos se sentaba un "chac" asiendo un mismo cordón. Luego santiguaban el espacio (Landa, 1973: 44). Pero las acciones y mecanismos de delimitación de los espacios rituales parecen ser algo inmanente a la celebración de ritos, cuando éstos se realizan en espacios que comúnmente no son sagrados. Entonces diríamos que se convierten precisamente en espacios rituales mediante su delimitación y purificación.

Con base en su interpretación de la primera serie de vueltas, tanto en términos de su sentido como del número según el género asignado al infante, Cervera afirma que en el hetzmek se representa la cosmovisión maya. También sostiene que este ritual "evoca la génesis maya" porque, según el mito de creación del mundo, los "Creadores y Formadores" crearon al hombre con maíz blanco y amarillo, y este alimento está presente en el hetzmek "para recordarle al niño su responsabilidad" de recordar, invocar y alimentar a los creadores (Cervera, 2006: 16).

Tomamos estas afirmaciones como hipótesis de trabajo. Tendríamos que investigar hasta qué punto el ritual del hetzmek expresa la cosmovisión de los mayas actuales y/o si expresa la concepción de los mayas antiguos; es decir, es necesario investigar más a fondo si las prácticas simbólicas actuales son supervivencias de concepciones antiguas, que pueden o no ser vigentes, pero que las prácticas continúan sin que los actores sepan completamente por qué las hacen.

Con la delimitación del espacio ritual, nos dice Cervera, igualmente se pretende abrir el camino del niño y construir su destino en el sentido expresado en los alimentos, los objetos y la forma de cargar al niño (Cervera, 2006: 15). Este sentido deseado es que "desarrollen su entendimiento y (...) recuerden su responsabilidad de ser respetuosos, generosos, rápidos y buenos en su trabajo, y capaces de pensar, aprender y hablar correctamente" (Cervera, 2000: 16).

Por último, Cervera propone que deben estudiarse cuáles son las concepciones de los padres en relación con la manera en la que se produce el desarrollo de los niños, el nivel de participación de los padres, de los propios niños, o de otras entidades anímicas en este proceso. Nuevamente aquí se refiere a una mentalidad maya que perdura y se expresa en el lenguaje. El conocimiento de estas concepciones, señala, puede ayudar al entendimiento del ritual del hetzmek.

Coincidimos con Cervera en que es necesario conocer las concepciones de los padres acerca de cómo se produce el desarrollo o la adquisición de conocimientos, habilidades, etcétera, para poder interpretar con cabalidad el ritual del hetzmek. Nos parece que estas concepciones tienen que expresarse en esta celebración cuyo propósito central es favorecer el desarrollo físico e intelectual de los niños. El conocimiento de estas concepciones también debe poder contribuir a explicar la continuidad de dicha práctica, así como acerca de los cambios que ha sufrido a lo largo del tiempo. Si el pensamiento maya se expresa en este ritual, es más fac- 
tible que sea a través de estas concepciones. En todo caso, sería una intermediación con concepciones cosmogónicas más alejadas de la vida terrenal y práctica.

Es precisamente a partir de nuestro interés por los procesos de socialización infantil, en los que indudablemente intervienen concepciones sobre la infancia, el desarrollo, el papel de los cuidadores y el papel de los propios niños en lo que ellos llegarán a ser de adultos, por lo que hemos incursionado en el estudio y análisis del ritual del hetzmek.

\section{Algunas reflexiones y recomendaciones metodológicas}

Después de haber hecho esta revisión y análisis de los textos y autores que, desde distintas problemáticas teóricas, se han ocupado del ritual del hetzmek, queremos dejar en claro cuál es nuestra postura al respecto, y hacer algunas recomendaciones metodológicas y analíticas, apoyadas en teóricos sociales que a nuestro juicio han hecho importantes aportes a la ciencia social: Peter Berger y Thomas Luckmann (1968), Pierre Bourdieu (1991), Anthony Giddens (1995) y Niklas Luhmann (1998).

Para conocer con qué propósito los padres realizan la ceremonia del hetzmek a sus hijos, tiene que recurrirse, por un lado, a entrevistas y pláticas con ellos y con personas más informadas de las localidades en estudio y, por otro lado, a la observación de varias celebraciones en distintos pueblos. Ambas fuentes de información tienen que compararse e interpretarse, tomando en cuenta que la primera fuente puede ayudar a interpretar a la segunda, y viceversa. Esta retroalimentación entre las fuentes de información es necesaria porque los actores, a pesar de que frecuentemente responden "es la costumbre", y que por eso la siguen, en cierta medida saben lo que hacen y por qué lo hacen, aunque no siempre puedan expresar este conocimiento en palabras y su conocimiento sea generalmente parcial (Bourdieu, 1991: 65 y 118; Giddens, 1995: 24 y 41-45). De modo que, las explicaciones y las razones de los informantes nos dan indicaciones sobre cómo interpretar sus prácticas, sus actos, los objetos simbólicos empleados en el ritual y la estructura de ésta, con bases y argumentos sólidos; ya que no toda interpretación es válida y confiable.

Por todo lo anterior, en la exposición de las razones por las cuales los actores realizan el ritual del hetzmek, hemos intentado distinguir entre la interpretación del investigador y la información discursiva proporcionada por los actores, por mucho que esta última ya haya pasado por un filtro de selección e interpretación por parte del primero. No todos los estudiosos del ritual reseñados anteriormente han tenido el cuidado de distinguir las razones argüidas por los informantes y las interpretaciones que ellos hacen de los actos y objetos simbólicos, y del ritual en su conjunto.

Igualmente adoptamos la propuesta de Bourdieu (1991: 21-24 y 160), para quien, antes de recurrir a explicaciones "teóricas", objetivistas o subjetivistas 
de los rituales, las cuales se derivan de las perspectivas analíticas de los mismos investigadores, se debe indagar el sentido práctico y las razones prácticas que los propios actores dan a sus actos. Para reconstruir este sentido práctico, el cual está presente en los diversos campos de acción del sujeto, es necesario comparar estos campos entre sí. Tratándose de rituales, deben compararse los distintos rituales que practica un mismo grupo porque en todos ellos se expresa un mismo sentido y una misma lógica práctica. Entonces, el simbolismo del ritual del hetzmek tendría que interpretarse en comparación con el simbolismo de otros rituales del mismo grupo social.

En este sentido, sin negar que la ceremonia del hetzmek pudiera expresar algunas reminiscencias de la cosmovisión maya, deben conocerse las razones y las explicaciones prácticas que pueden resultar mucho más plausibles y cercanas a los intereses, necesidades, conocimientos, sentimientos de los actores. Por otra parte, hay que tener cuidado cuando se hacen comparaciones entre tiempos y espacios tan distantes; épocas prehispánica y contemporánea, en el primer caso, y Yucatán con Chiapas y Guatemala, en el segundo. Tenemos que tener en cuenta que la "cosmovisión maya" es una construcción teórica hecha para una época y a partir de información reunida en áreas culturales cuya conexión está documentada. ¿Qué tan válido es explicar fenómenos rituales actuales con información reunida en otros espacios y tiempos con los que ya no hay tal conexión?

Nuestra recomendación va en el sentido de tener cuidado con los presupuestos de los que partimos en las investigaciones. Algunos estudiosos rechazan el análisis de la cultura maya a partir de parámetros de la sociedad occidental, lo cual es válido en cierto sentido. Ésta ha sido una preocupación de la antropología y de la mayoría de los antropólogos, desde Franz Boas y sus seguidores. Pero debemos tener en cuenta otro peligro: la invención y atribución de significados que poco o nada tienen que ver con las formas de pensar de los actores actuales, intentando preservar una diferencia que posiblemente se ha desdibujado o que se ha construido de otro modo. También debemos pensar en la posibilidad de que el origen de prácticas culturales actuales esté, al menos parcialmente, en otras matrices culturales.

En relación con las políticas culturales de revaloración de las culturas indígenas, la maya entre éstas, queremos recomendar que no debe forzárseles a revivir un supuesto pasado, una forma de pensamiento y acción, que posiblemente existió, pero que ya no le dice nada a los actores actuales. Habría que preguntarse a quién conviene esas vueltas al pasado.

Si el modo de pensamiento maya perdura, o en qué medida perdura, hay que investigarlo. Para ello será necesario diseñar técnicas de investigación más creativas. Éste es un reto para los interesados en este tema y es también una tarea por realizar. 


\section{BIBLIOGRAFÍA}

\section{Barrera Vásquez, Alfredo}

1980 Diccionario Maya Cordemex. Mérida, Yucatán: Ediciones Cordemex.

Berger, Peter y Thommas Luckmann

1968 La construcción social de la realidad. Buenos Aires: Amorrortu.

Bonavides Mateos, Enrique

1992 "Ritos de pasaje entre los mayas antiguos", Estudios de Cultura Maya XIX: 397-425. México: UNAM, IIFL, Centro de Estudios Mayas.

Bourdieu, Pierre

1988 Cosas dichas. Buenos Aires: Gedisa.

1991 El sentido práctico. Madrid: Taurus.

Bracamonte y Sosa, Pedro y Jesús Lizama Quijano

2006 Tocando fondo. Resultados básicos de la encuesta sobre marginalidad, pobreza e identidad del pueblo maya. Mérida, Yucatán: Centro de Investigaciones y Estudios Superiores en Antropología Social (Colección Peninsular, Serie Perspectivas).

Carrithers, M.

2001 "Sociality: Anthropological Aspects", International Encyclopaedia of the Social \& Behavioral Sciences, pp. 14500-14504, Neil J. Smelser y Paul B. Baltes (eds.). Amsterdam: Elsevier.

Cervera Montejano, María Dolores ${ }^{19}$

2006 'El hetsmek' como expresión simbólica de la construcción de los niños mayas yucatecos como personas" (s.p.i.), 27 p.

De la Garza, Mercedes

1998 Rostros de lo sagrado en el mundo maya. México-Buenos Aires-Barcelona: Paidós.

Diario de Yucatán, 17 de enero de 2006.

Diario de campo, 18-20 de diciembre de 2000.

Florescano, Enrique

1999 "Antiguas y nuevas imágenes de los mayas", Letras Libres, sept., pp. 58-62.

Fortuny, Patricia

2004 "Transnational Hetzmek': Entre Oxkutzcab y San Pancho", Estrategias identitarias: educación y la antropología histórica en Yucatán, pp. 225-254, Juan A.

Castillo Cocom y Quetzil E. Castañeda (eds.). Yucatán-México: Universidad

\footnotetext{
${ }^{19} \mathrm{La}$ autora nos entregó una copia de esta ponencia, pero no el nombre del congreso donde fue presentada.
} 
Pedagógica Nacional/ The Open School of Ethnography and Anthropology / Secretaría de Educación del Estado de Yucatán.

Giddens, Anthony

1995 La constitución de la sociedad. Bases para la teoría de la estructuración. Buenos Aires: Amorrortu.

Kirk, Carlos R.

1982 Haciendas en Yucatán. México: Instituto Nacional Indigenista.

Landa, Diego de

1973 Relación de las cosas de Yucatán. México: Porrúa.

Luhmann, Niklas

1998 Los sistemas sociales. Lineamientos para una teoría general. Barcelona: Anthropos.

Máas Collí, Hilaria

1983 "Transmisión cultural. Chemax, Yucatán. Un enfoque etnográfico". Tesis de licenciatura en Ciencias antropológicas, Escuela de Ciencias Antropológicas de la Universidad de Yucatán, Mérida.

1986 "La endoculturación en la infancia y adolescencia en Chemax, Yucatán", Revista de la Universidad Autónoma de Yucatán 159: 3-15, oct.-dic. Mérida, Yucatán.

Marion, Marie-Odile

1994 Identidad y ritualidad entre los mayas. México: Instituto Nacional IndigenistaSecretaría de Desarrollo Social.

Morley, Sylvanus G.

1974 La civilización maya. México: FCE.

Pacheco Cruz, Santiago

1934 Estudio etnográfico de los mayas del ex territorio de Quintana Roo: su incorporación a la vida nacional. Mérida, Yucatán: Imprenta Oriente.

Peón Arceo, Alicia

2000 "Rituales de vida en Tuzik, Quintana Roo", Temas Antropológicos 22 (1): 54 77. Mérida, Yucatán.

Prieto,Virginia

2007 "Procesos de identificación étnica y socialización: niños y jóvenes de un albergue escolar indígena en Yucatán". Tesis de licenciatura en Ciencias antropológicas, Universidad Autónoma de Yucatán.

Quintal, Ella Fanny, et al.

2003 "Solares, rumbos y pueblos: organización social de los mayas peninsulares", La comunidad sin límites. Estructura social y organización comunitaria en las re- 
giones indígenas de México, pp. 291-382, Saúl Millán y Julieta Valle (coords.). México: INAH.

Redfield, Robert

1944 Yucatán. Una cultura de transición. México: FCE.

y Alfonso Villa Rojas

1962 Chan Kom. A Maya Village. Chicago \& Londres: University of Chicago Press.

Romero de Nieto, Carmen

1986 El Jet's mek'. México: Dirección General de Culturas Populares.

Ruz Lhuillier, Alberto

1974 La civilización de los antiguos mayas. La Habana: Editorial de Ciencias Sociales.

Thompson, Richard A.

1974 Aires de progreso: cambio social en un pueblo maya de Yucatán. México: Instituto Nacional Indigenista.

Thompson, J. Eric S.

1979 Historia y religión de los mayas. México: Siglo XXI.

Villa Rojas, Alfonso

1978 Los elegidos de dios. Etnografia de los mayas de Quintana Roo. México: Instituto Nacional Indigenista.

1968 "Los conceptos de espacio y tiempo entre los grupos mayances contemporáneos", Tiempo y realidad en el pensamiento maya, pp. 119-167, Miguel León-Portilla. México: UNAM.

1971 "Patrones culturales mayas antiguos y modernos en las comunidades contemporáneas de Yucatán", Desarrollo cultural de los mayas, pp. 353-385, Evon Z. Vogt y Alberto Ruz L. (eds.). México: UNAM.

1995 Estudios etnológicos. Los mayas. México: UNAM, Instituto de Investigaciones Antropológicas.

Villanueva Villanueva, Nancy Beatriz

2004 "Socialización infantil: cognición, cultura e identidad". Tesis de doctorado, Escuela Nacional de Antropología e Historia, México.

(en prensa) "La revaloración de la cultura maya en Yucatán", Temas Antropológicos 30 (1). Mérida, Yucatán. 


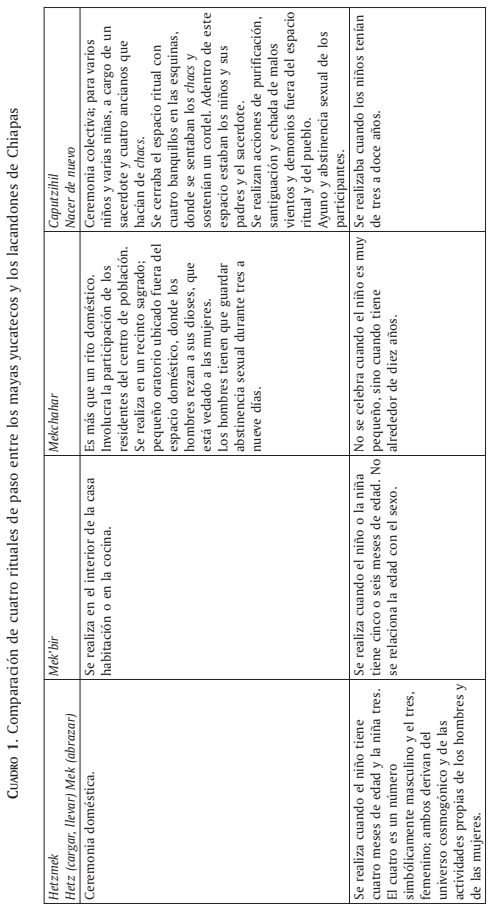




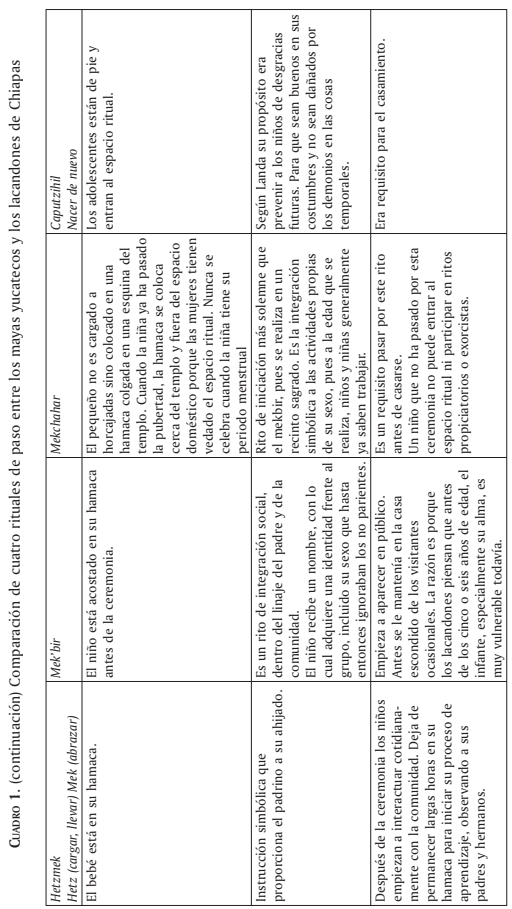




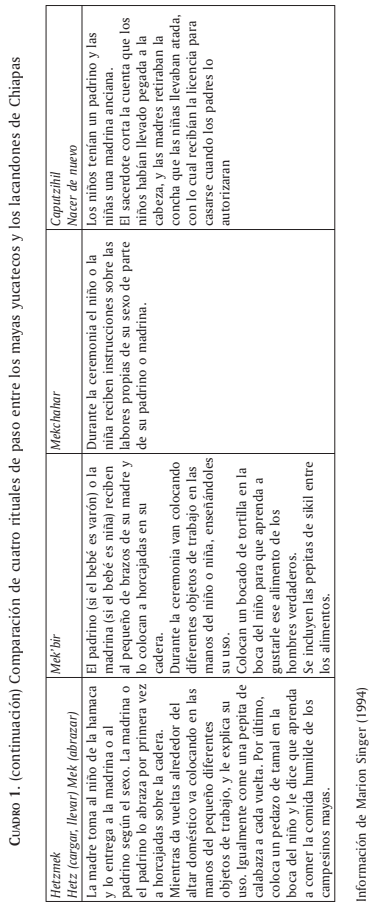

